\title{
Work In Progress: How Engineering Students Collaboratively Seek Information in an Engineering Design Course?
}

\author{
Nasser Saleh \\ Integrated Learning Librarian, \\ Engineering \& Science Library \\ Queen's University \\ nasser.saleh@queensu.ca
}

\begin{abstract}
The paper reports a research in progress to study collaborative information seeking practice of learners working in groups in a senior design project course. The research belongs to the area of educational informatics where information behaviour is studied within a learning environment. The paper presents the definition of collaboration and the conceptual models of collaborative information behaviour.
\end{abstract}

\section{Introduction}

The information space has dramatically changed in the last years with the use of web-based resources and the availability of electronic formats for traditional library print materials. Students are more familiar on using web technologies more than using library materials to find appropriate materials for their research and for their projects. Although digital technologies are mainly designed to support one single user working alone; engineering students working on a project always collaborate to find information and use them during the lifetime of their projects.

The area of research on Collaborative Information Behaviour (CIB) has recently emerged to focus on how individuals directly or indirectly collaborate with other users in seeking, retrieve and use information. Studies that contribute to research on CIB have been done in different fields in addition to Library and Information Science (LIS) such as: collaborative learning, human-computer interaction, communications, organizational behaviour, decision support systems, knowledge management, computersupported collaborative work (CSCW), computersupport collaborative learning (CSCL), and educational technology. The paper presents a work in progress that focus to find answers on how do undergraduate students identify their information needs collaboratively in an engineering design course?, how do collaborative information behaviour activities manifest themselves in such a course?, and what types, forms, and attributes of collaborative information needs activities can be observed, identified, and supported by technology?

The situation of a design project group makes the research more focused on groups but individual information seeking will be touched on as well, but the main focus is on the role of the group, with a hypothesis that some collaboration and information sharing takes place based on my pre-research observations and based on how digital technologies can improve the process and outcomes of collaborative information seeking practice in an engineering educational setting.

\section{Research Objectives}

The research main questions are

1. How do undergraduate students identify their information needs collaboratively in a projectbased engineering course?

2. How do collaborative information behaviour activities manifest themselves in an undergraduate project-based course?

3. What types, forms, and attributes of collaborative information needs activities can be observed, identified, and supported by technology?

My original motivation can be recognized in the first question: a deep interest in how undergraduate engineering students seek information, formally or informally while they work as a group in a senior engineering design course. I also want to explore how the nature of the required information for their project affects their information seeking, searching and use as they have to consult different resources. The situation of a design project group makes the research 
more focused on groups but individual information seeking will be touched on as well, but the main focus is on the role of the group.

The second question concentrates on collaborative information behaviour discovered in groups. My hypothesis is that some collaboration and information sharing takes place based on my pre-research observations, but I intend to explore how and to what extent they occur during the project. Here I also ask what factors seem to influence collaboration in identification of information needs, information seeking, searching and use and how technology would support collaborative information behaviour, or to promote collaboration, or maybe restrain collaboration?

The third question focuses on the nature and attribute of the observed activities, if they exist and easily observed, and how technology did support student in identifying their information needs.

\section{Collaborative Information Behaviour}

Wilson [1] defines Information Behaviour as the study of how people need, seek, give, and use information in different contexts, including the workplace and everyday living. Wilson [2] further defined information behaviour as "the totality of human behaviour in relation to sources and channels of information, including both active and passive information seeking and information use." The first definition is useful when describing that research in information behaviour to include the research in information seeking, information retrieval, and information use, while the second definition is more accepted in describing the active and passive activities in information seeking and use, which are major parts in studying collaborative information behaviour.

Collaborative Information Behaviour (CIB): is the core of this research, while there are many definitions for collaborative information behaviour, this study will following the definition of collaborative information behaviour by [3] as "collaborative information behaviour can be broadly defined as an activity where two or more actors communicate to identify information for accomplishing a task or solving a problem. .. it includes processes of problem identification, analysis of information need, query formulation, retrieval interactions, evaluation, presentation of results, and applying results to resolve an information problem".

\section{Defining Collaboration in Information Behaviour}

Many studies in collaborative information behaviour have emerged recently, but few researchers have considered defining collaboration per se in Information Science. The term "collaboration" has been used intuitively and interchangeably with other terms such as "coordination" and "cooperation" [4], [5]. A clear definition of collaboration in information behaviour is needed to identify what is to be considered collaborative information behaviour activities.

Collaboration can be described as a process through which parties who see different aspects of a problem can constructively explore their differences and search for solutions that go beyond their own limited vision of what is possible [6]. Another study [7], defines collaboration as a mutually beneficial relationship between two or more parties who work toward common goals by sharing responsibility, authority, and accountability for achieving results. This research will use the definition of collaboration as "human behaviour that facilitates the sharing of meaning and completion of activities with respect to a mutually shared superordinate goal and which takes place in a particular social, or work, setting" [8].

Given that that collaboration can not be easily achieved or guaranteed to happen in any situation, Sonnenwald [9] introduced the concept of "contested collaboration" to characterize the communication among the work team members. The nature of contested collaboration can guide the research on collaborative information behaviour to focus on explicit and implicit activities as well. Surowiecki [10] describes four conditions for a successful collaboration to happen:

1. Diversity of opinion. Each person should have some private information, even if it is just an eccentric interpretation of known facts.

2. Independence. People's opinions are not determined by the opinions of those around them.

3. Decentralization. People are able to specialize and draw on local knowledge.

4. Aggregation. Some mechanism exists for turning private judgments into a collective decision.

The notion of contested collaboration created originally by Sonnenwald was later adapted by Hara et al. [4] who studied scientists' perspectives on collaboration and concluded that collaboration can be seen as a continuum from complementary collaboration to integrative collaboration. In the case 
of complementary collaboration, some kind of division of a project occurs. When collaboration can be characterized as integrative, a fully integrated and shared project takes place. The researchers developed a typology of collaboration as shown in Figure 1.

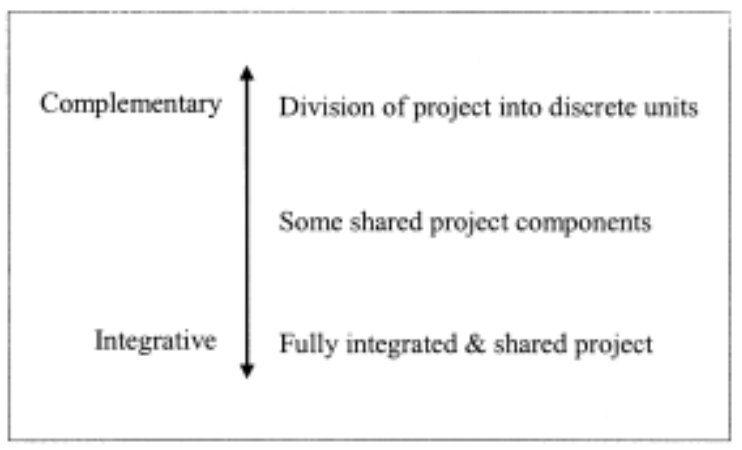

Figure 1: A Typology of Collaboration [4]

Hara et al, have also identified several factors that affect collaboration and its potential to shift collaboration from complementary to integrative, of which compatibility was one of the most important. Complementary collaboration required personal compatibility with respect to work style, writing style, and work priority. Fully integrative collaboration required even more: compatibility in the approach to science and compatibility of personality. This often included personal friendship and trust that comes with friendship. The other factors included work connections, incentive, and socio-technical infrastructures. The factors and their impacts on collaboration are represented in Figure 2.

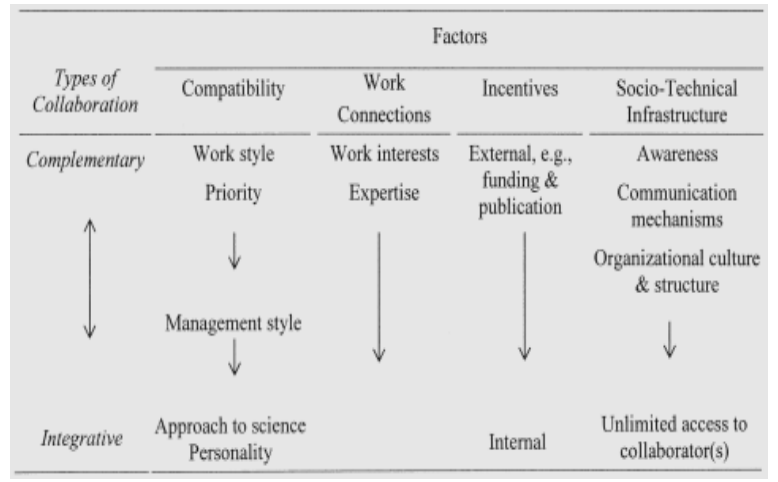

Figure 2: Factors influencing the different types of collaboration. [4]

To distinguish between the characteristics of collaboration, cooperation, coordination, contribution, and communication in information behaviour, Shah [5] developed a model for collaboration as shown in Figure 3.

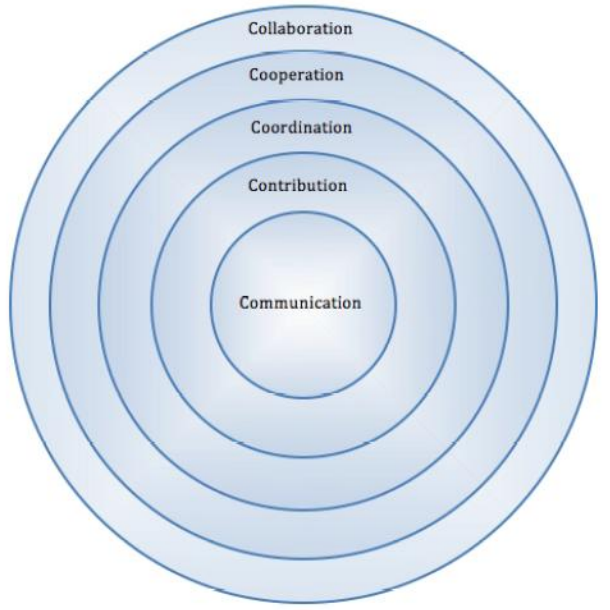

Figure 3: Shah's Model of Collaboration

The model consists of five layers, with collaboration encapsulating the other four layers. The characteristics of the five layers according to Shah are described in Table 1.

Table 1: Characteristics of Shah's Model Layers

\begin{tabular}{|l|l|}
\hline Layer & \multicolumn{1}{|c|}{ Description } \\
\hline 1.Communication & $\begin{array}{l}\text { This is a process of sending or } \\
\text { exchanging information, which is one } \\
\text { of the core requirements for carrying } \\
\text { out collaboration, or maintaining any } \\
\text { kind of productive relationship for that } \\
\text { matter. }\end{array}$ \\
\hline 2.Contribution & $\begin{array}{l}\text { This is an informal relationship by } \\
\text { which individuals help each other in } \\
\text { achieving their individual goals }\end{array}$ \\
\hline 3.Coordination & $\begin{array}{l}\text { This is a process of connecting parties } \\
\text { together for a harmonious action. This } \\
\text { often involves bringing people under } \\
\text { an umbrella at the same time and } \\
\text { place, during this process; the } \\
\text { involved parties may share resources, } \\
\text { responsibilities, and goals. }\end{array}$ \\
\hline 4.Cooperation & $\begin{array}{l}\text { This is a relationship in which parties } \\
\text { with similar interests take part in } \\
\text { planning activities, negotiating roles, } \\
\text { and sharing resources to achieve joint } \\
\text { goals. In addition to coordination, } \\
\text { cooperation involves all the parties } \\
\text { following some rules of interaction }\end{array}$ \\
\hline
\end{tabular}




\begin{tabular}{|l|l|}
\hline 5.Collaboration & $\begin{array}{l}\text { This is a process of involving parties } \\
\text { that may see different aspect of a } \\
\text { problem. They engage in a process } \\
\text { through which they can go beyond } \\
\text { their own individual expertise and } \\
\text { vision by constructively exploring } \\
\text { their differences and searching for } \\
\text { common solutions. In contrast to } \\
\text { cooperation, collaboration involves } \\
\text { creating a solution that is more than } \\
\text { merely the sum of each party's } \\
\text { contribution }\end{array}$ \\
\hline
\end{tabular}

This model shows the relationship between the five layers and how a clear definition of collaboration could help research on collaborative information behaviour for this research.

\section{Conceptual Model for Collaborative Information Behaviour}

There are many developed conceptual models for individual information behaviour and the study of collaborative information behaviour will focus on the group information behaviour that can be affected by many factors.

The research is primarily guided by Allen's integrated 'person-in-situation' information behaviour model [11] , [12], Bryce Allen developed this model, according to which individual and social variables are combined into an integrated model, thus representing an integrated view on the individual's problem situation that may help understand the situated individual group member. The focus of the model is on individuals' information needs, but as pointed out by [12], a unified and coherent understanding of information needs can only be obtained as researchers consider the "problem situations" that give rise to needs and the information seeking behaviours that resolve those needs, in terms of interactions between personal and situational variables.

This model describes information needs as explanatory constructs that are determined by certain goals, purposes or objectives, explaining why people behave and act as they do. Information needs occur in many different situations and there are many ways that people experience information needs, given that "people are simultaneously individuals and members of groups" [13]. The model has the advantage to distinguish two types of information needs; information needs that occur at the individual level and those occur within groups of various kinds. Both types of needs are influenced by personal, social factors as well as situational factors (outer context). As a result Allen proposed a model to integrate both of personal and social/situational factors in information behaviour, arguing that both personal and social/situational variables interact in generating information behavior and therefore should be integrated.

The four approaches to information needs in this model are the cognitive, the social, the social cognitive and the organizational approach as shown in Figure 1.

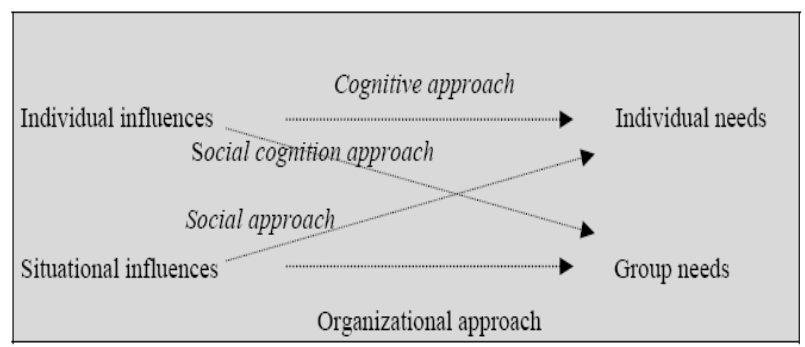

Figure 4: Allen's Integrated 'person-in-situationbehaviour' Model [12]

The four approaches to information needs in Allen's model can be described as:

- The cognitive approach describes the relation between individual influences and individual behaviour. It seeks to explain behavior by reference to what people think and know and the cognitive processes involved in thinking, learning and problem solving. In a later study [14], the cognitive approach was defined defines as an approach and set of constructs for understanding information behaviour, which focuses fundamentally upon attributes of the individual.

- The social approach describes the relation between social situational influences and individual behavior, emphasizing the social embedment of the process of defining and meeting needs: “... Since people are always embedded in social situations, it is sometimes difficult to distinguish clearly between the influences on information seeking behavior that are individual and those that are social" [12].

- The social-cognitive approach describes the relation between individual influences and group behavior and the collective nature of information needs. A group may have information needs that go beyond the individual information needs of its members, but group needs do not replace the individual needs; rather, group and individual needs may occur concurrently.

- The organizational approach describes the relation between situational influences and group 
behaviour as a group may be influenced by its larger situational and social context.

The implementation oft his model in this research on engineering design course learners will consider the group member as an individual affected by inner cognitive influences (personal factors) but at the same time affected by the influences from other group members (social factors). The cognitive individual influences can be reshaped within the group influences (socio-cognitive factors). At the same time, the individual as well as the group may be influenced by 'outer-factors', that is the work task situation or the organization (situational factors such as the project task, its complexity .. etc).

Allen's integrated model of information behaviour provide many useful insights in studying collaborative information behaviour, identifying four major approaches in studying information behaviour in a group.

\section{The Holistic Model of Information Behaviour}

A holistic cognitive framework for research in information behaviour was developed by Ingwersen and Järvelin [15]. This framework reflects an understanding of information seeking and retrieval as a process, involving various cognitive and emotional actors or teams in context. The developed framework is shown in Figure 2.

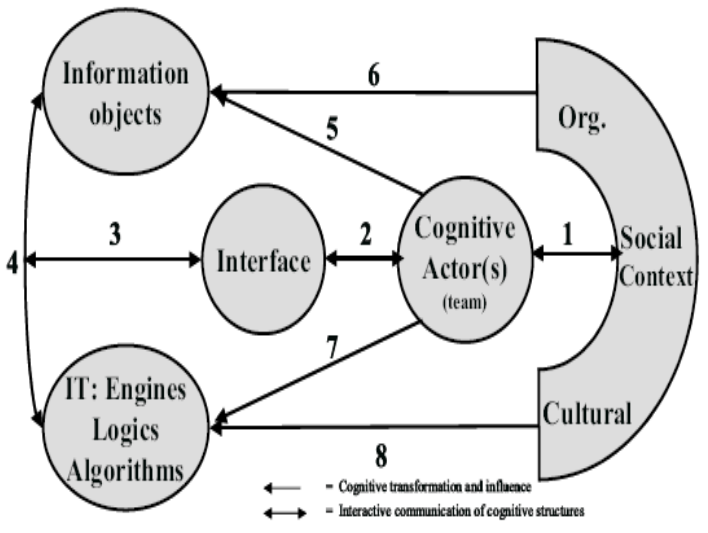

Figure 2: Interactive Information Seeking, Retrieval and Behavioural Processes.

The arrow numbers in the model represent the followings:

- The work task dimension covers the work task set by the organization, the social organization of work, collaboration between actors and the physical/system environment.
- The search task dimension covers necessary seeking and retrieval practices, as understood collectively in the organizational practice.

- The actor dimension covers the actor's declarative knowledge and procedural skills, and other personal traits as well-motivation, emotions.

- The perceived work task dimension covers the actor's perception of the work task-forming the task that is really being carried out.

- The perceived search task dimension covers the actor's perception of the search task including information need types regarding the task and its performance process and perceived information space.

- The document dimension covers document contents and genres and collections in various languages and media, which may contain information relevant to the task as perceived by the actor.

- The algorithmic search engine dimension covers the representation of documents or information and information needs. It also covers tools and support for query formulation and methods for matching document and query representations.

- The algorithmic interface dimension covers tools for visualization and presentation of information objects, collections and their organization.

The model emphasizes the information processes involved in information seeking and retrieval, but also encompasses processes of information behavior, such as use, creation and communication. It consists of five central components, each consisting of data structures representing the cognitive structures of the actors involved in their generation, maintenance and modifications over time: The socio-organizational context may frame or interact with 1) the cognitive actor (individual or a team), 6) the information space holding objects of potential information value to the information seeker and 8) the IT-settings.

Also, the cognitive actor (or a team of actors) operates in, and is influenced by a dual contextual frame: the IT and information spaces surrounding the actor which are 2) the interface, 5) the information space and 7) the IT settings and the socio-cultural organizational context 1) social context. Further, the interface may interact with 3 ) the system side, which is both of the information space and the IT settings. Finally, 4) these two actors may interact as well.

Ingwersen and Järvelin describe this holistic framework by being not static, but flexible in the sense that it opens up for the study of many and different relationships, involving few or many components. They give examples that when the actor 
(user) in focus changes, the contextualizing actors of important changes change accordingly. They argue that the model can be a framework for many research issues and theory to be generated.

\section{Research Method}

This research contributes to the fields of information science, design engineering, and engineering education. This area of research is defined as Educational Informatics where there is an intersection of information science, education and information \& communication technology as a model of learning-related information behaviour. The model details components of such behaviour, including: basic information processes, information processing types and information processing approaches; and factors affecting information behaviour relating to educational environments (in particular, learning objectives) and mental (including cognitive and affective) states. The complexity of information needs and associated relevance judgments implied are included in this research area [16], [17].

The research is an action research that aims to improve student's information practice during a design engineering course and to give them some of the required skills for lifelong learning, also it will improve the practice of academic librarians in supporting design courses in engineering; the selected method meets the definition of action research as "a participatory, democratic process concerned with developing practical knowing in the pursuit of worthwhile human purposes, grounded in a participatory worldview" [18] . Action research is an approach where the research participants are involved actively to investigate their practice in a real-world situation, which makes such a research to be a research in action and not a research about action. Action research is not a new emerging research method; it has been viewed as early as in 1947 by K. Lewin [19] as a cyclical, dynamic, and collaborative process in which people address their lives and the social issues affecting them. The outcomes of action research can not be seen only as possible solutions to existing problems or challenges but also as an important learning practice from both the intended and unintended outcomes. The need of the research is coming from a current practice that needs to be improved and to develop the skills of our students to meet the demand of highly skilled knowledgeable engineers and the requirements from engineering accreditation boards.

\section{Next Steps}

The paper presents a work on progress to research on collaborative information behaviour of learners in an undergraduate design engineering course. Preliminary observations and pilot data collection started in winter 2009 and will continue through the fall semester to define the appropriate methodology for data collection and then analysis.

\section{References}

[1] T. D. Wilson, "Models in information behaviour research," Journal of Documentation, vol. 55, pp. 249-270, 1999.

[2] T. D. Wilson, "Human information behavior," Informing Science, vol. 3, pp. 49-55, 2000.

[3] S. Talja and P. Hansen, "Information Sharing," New Directions in Human Information Behavior, pp. 113-134, 2006.

[4] N. Hara, P. Solomon, S. L. Kim and D. H. Sonnenwald, "An emerging view of scientific collaboration: Scientists' perspectives on collaboration and factors that impact collaboration," J. Am. Soc. Inf. Sci. Technol., vol. 54, 2003.

[5] C. Shah, "Toward collaborative information seeking (CIS)," in Joint Conference on Digital Libraries (JCDL) Workshop on Collaborative Information Retrieval. 2008.

[6] B. Gray, Collaborating: Finding Common Ground for Multiparty Problems. San Francisco: Jossey-Bass, 1989.

[7] D. D. Chrislip and C. E. Larson, Collaborative Leadership: How Citizens and Civic Leaders can make a Difference. San Francisco: Jossey-Bass, 1994.

[8] M. Iivonen and D. H. Sonnenwald, "The use of technology in international collaboration: Two case studies." in Proceedings of the $63^{\mathrm{Rd}}$ ASIS Annual Meeting, 2000, pp. 78-92.

[9] D. H. Sonnenwald, "Contested collaboration: a descriptive model of intergroup communication in information system design," Information Processing and Management, vol. 31, pp. 859-877, 1995.

[10] J. Surowiecki, The Wisdom of Crowds: Why the Many are Smarter than the Few and how Collective Wisdom Shapes Business, Economies, Societies, and Nations. Doubleday Books, 2004.

[11] B. Allen, Information Tasks: Toward a User-Centered Approach to Information Systems. San Diego, CA: Academic Press, 1996.

[12] B. Allen, "Information needs: A person-in-situation approach," in Proceedings of an International Conference on Information Seeking in Context, 1997, pp. 111-122. 
[13] B. Allen and K. S. Kim, "Person and context in information seeking: interactions between cognitive and task variables: the new review of information behaviour research," Studies of Information Seeking in Context, vol. 2, pp. 1-16, 2001.

[14] K. E. Pettigrew, R. Fidel and H. Bruce, "Conceptual Frameworks in Information Behavior." Annual Review of Information Science and Technology (ARIST), vol. 35, pp. 43-78, 2001.

[15] P. Ingwersen and K. Jarvelin, The Turn: Integration of Information Seeking and Retrieval in Context. Springer, 2005 ,
[16] P. Levy, N. Ford, J. Foster, A. Madden, D. Miller, M. B. Nunes, M. McPherson and S. Webber, "Educational Informatics: An Emerging Research Agenda," J. Inf. Sci., vol. 29, pp. 298, 2003.

[17] N. Ford, "Towards a model of learning for educational informatics," Journal of Documentation, vol. 60, pp. 183225, 2004.

[18] P. Reason and H. Bradbury, The SAGE Handbook of Action Research: Participative Inquiry and Practice. Sage Pubns Ltd, 2007.

[19] K. Lewin, "Action research and minority problems," J. Soc. Iss., vol. 2, pp. 34-46, 1946. 